\title{
Diseño y Evaluación de una Actividad para Desarrollar el Trabajo en Equipo en Primero de Turismo de la EPSG
}

\author{
Alberto Palomares Chusta ${ }^{a}$, Ana Ábalos Galcerá ${ }^{b}$ \\ åDepartamento de Sistemas Informático y Computación, UPV, apalomares@dsic.upv.es \\ bInstituto de Ciencias de la Educación, UPV, ana@ice.upv.es.
}

\begin{abstract}
Resumen
En este trabajo presentamos el diseño, desarrollo y evaluación de una actividad para trabajar la competencia "Trabajo en Equipo y Liderazgo" (CT6). Esta actividad se desarrolló en el marco de una Sesión Tutorial del programa PATU (Plan de Acción Tutorial Universitario) de la UPV, durante el primer cuatrimestre del curso 2016-2017, en la asignatura Informática de Gestión (IG) del primer curso del Grado de Turismo (GT) que se imparte en de la Escuela Politécnica Superior de Gandia (EPSG). El objetivo principal era trabajar y evaluar la CT6 con el requisito de que la actividad propuesta estuviera integrada con los contenidos propios de la asignatura. La actividad consistió en la preparación, en un periodo de tiempo limitado (30 minutos), de una única presentación sobre el turismo en la provincia de Valencia. Para coordinar el desarrollo de la actividad se asignaron diferentes roles a los alumnos en función de su posición en la clase. Los alumnos tuvieron que preparar pequeñas presentaciones sobre temáticas y zonas especificas, que se fueron integrando en presentaciones más amplias hasta tener una única presentación. El resultado fue evaluado por los alumnos mediante una encuesta de satisfacción que puso de manifiesto el cumplimiento de los objetivos previstos.
\end{abstract}

Palabras clave: Competencia Transversal, Trabajo en Equipo, Liderazgo, Punto de Control, Tutoría, Grado en Turismo, Rol, Coordinación, 


\section{Introducción}

La Universitat Politècnica de València (UPV) se encuentra inmersa en un proyecto institucional que tiene como objetivo principal desarrollar y acreditar las denominadas Competencias Transversales (CT) a los estudiantes egresados en cualquiera de los títulos oficiales impartidos en la UPV ${ }^{1}$. Las $13 \mathrm{CT}$ definidas en este proyecto son las siguientes:

1. Comprensión e integración (CT1).

2. Aplicación y pensamiento práctico (CT2).

3. Análisis y resolución de problemas (CT3).

4. Innovación, creatividad y emprendimiento (CT4).

5. Diseño y proyecto (CT5).

6. Trabajo en equipo y liderazgo (CT6 $)^{2}$.

7. Responsabilidad ética, medioambiental y profesional (CT7).

8. Comunicación efectiva (CT8).

9. Pensamiento crítico (CT9).

10. Planificación y gestión del tiempo (CT10).

11. Aprendizaje permanente (CT11).

12. Conocimiento de problemas contemporáneos (CT12).

13. Instrumental específica (CT13).

Graduados y empleadores no han dudado en subrayar la gran importancia que tienen estas CT en el desempeño profesional de los egresados. Por esta razón los nuevos títulos de grado y posgrado que se imparten en la UPV incorporan, de manera explícita, la exigencia de que los estudiantes sean formados en estas CT y que sea evaluado su nivel de logro (Blanco, 2009; Cano, 2008; De Miguel, 2006; Sánchez, 2010). Existen tres líneas para incorporar las $\mathrm{CT}$ en los estudios:

- En los propios planes de estudios ${ }^{3}$.

- En los trabajos final de grado (TFG) o de master (TFM).

- Mediante actividades extracurriculares.

Para su incorporación en los planes de estudio, las Estructuras Responsables del Título (ERT) asignan estas $\mathrm{CT}$ a las distintas materias/asignaturas que conforman el plan de estudios de una titulación, garantizando que se desarrollan y evalúan todas las CT en el plan, realizando un proceso de seguimiento y revisión, a través de la CAT, para comprobar que se está realizando correctamente. La evaluación de las CT se realiza en determinadas materias/asignaturas seleccionadas y que se denominan puntos de control (PC). Sin embargo es importante señalar que las CT se tienen que trabajar y desarrollar en diferentes asignaturas de una titulación, no sólo en las que son PC específico de alguna CT.

\footnotetext{
1 http://www.upv.es/contenidos/COMPTRAN/

${ }^{2}$ En este trabajo nos centraremos en la competencia CT6

${ }^{3}$ En este trabajo nos centraremos en la incorporación de la CT6 en los propios planes de estudio
} 
En general, todas las asignaturas deberían diseñar y desarrollar actividades que permitieran ir trabajando alguna CT. Lógicamente estas actividades tienen que estar relacionadas con los contenidos de las propias asignaturas. Además, para que los alumnos adquieran progresivamente las CT durante su todo periodo formativo en la UPV hay que empezar a desarrollar este tipo de actividades desde el primer curso de las titulaciones.

Los alumnos de primero requieren de un tratamiento especial. La dificultad del proceso de transición de secundaria a la universidad provocó la puesta en marcha, en la UPV, de algunas iniciativas institucionales que facilitaran al alumnado ese proceso de cambio, como por ejemplo el denominado Programa INTEGRA ${ }^{4}$, que consta, a su vez, de dos acciones: las Jornadas de Acogida y el Plan de Acción Tutorial Universitario (PATU) ${ }^{5}$.

El programa PATU ha experimentado recientemente un cambio metodológico en su implementación en la EPSG, con el objetivo de relacionar las tutorías con el desarrollo preliminar de algunas $\mathrm{CT}$ en determinadas asignaturas obligatorias de primer curso. Para hacerlo se han introducido, dentro del horario lectivo de estas asignaturas, las denominadas "Sesiones Tutoriales" en las que se trabajan específicamente algunas de las CT. Si prestamos atención al término "competencia", veremos que la competencia implica:

- Integración de conocimientos, puesto que requieren la adquisición de conocimientos, habilidades, actitudes, etc.

- Ejecución, puesto que se desarrollan en la práctica.

- Contextualización, puesto que se es competente en situaciones concretas en cuanto a espacio, tiempo y circunstancias. No son generalizables.

- Progresión, en el sentido de que de aquiere de forma paulatina, mediante la formación y la experiencia.

- Toma de decisiones, porque implican reflexión dirigida a una ejecución efectiva.

Como profesores debemos plantear situaciones de enseñanza-aprendizaje que permitan a los alumnos adquirir este tipo de aprendizaje práctico, contextualizado, progresivo y reflexivo. Y esto, no lo podemos conseguir mediante métodos tradicionales de enseñanza. Hemos de crear los escenarios pertinentes para la adquisición de este tipo de aprendizajes.

Esto lo conseguimos seleccionando estrategias de enseñanza que estén relacionadas con el tipo de aprendizaje que queremos promover. Si queremos que los alumnos aprendan a trabajar en equipo tendremos que diseñar actividades de enseñanza-aprendizaje $\mathrm{y}$ evaluación que pongan a los alumnos en situación de trabajar junto con sus compañeros en algún tema de la asignatura. $\mathrm{Y}$ esto es lo que se ha perseguido con el desarrollo de esta actividad. Una actividad de aprendizaje cooperativo informal, es aquella que se desarrolla en un momento puntual.

\footnotetext{
${ }^{4}$ https://www.upv.es/perfiles/futuro-alumno/integra-patu-es.html

${ }^{5}$ Este trabajo nos centraremos en actividades relacionadas con el programa PATU de la UPV.
}

\begin{tabular}{|l|l|}
\hline (cc) EY-NC-ND 2017, UPV &
\end{tabular} 
El aprendizaje en equipo es fundamental para los alumnos (Borrell, 2007; Exley, 2007; Serrano, 1996; Slavin, 1999; West, 2003). Tal y como señala (Barkley, 2007) la investigación sobre el aprendizaje en equipo en la educación superior, aunque limitada, es concluyente: los alumnos que estudiaron en pequeños equipos demostraron mayor rendimiento, mayor constancia y unas actitudes más favorables con respecto al aprendizaje que aquellos que lo hicieron en un sistema de enseñanza tradicional (Springer, 1999).

Los mismos autores afirman que un gran número de estudios evidencia que los alumnos que estudian en interacción con sus compañeros muestran unas actitudes más positivas hacia la asignatura, mayor motivación para aprender la materia así como una mayor satisfacción con su experiencia de aprendizaje (Johnson, 1991). Además aprecian más al profesor tanto a nivel académico como personal (Fiechtner, 1992 y Johnson, 1991).

Por último, exponen que el trabajo en grupos cooperativos está relacionado con el progreso percibido en el desarrollo personal, el aprecio de las bellas artes, las CT analíticas y la comprensión de las ciencias y la tecnología (Cabrera, 2008). Veremos cómo la valoración de sus participantes (tutores, tutelados y coordinadores) nos da información del impacto del programa y nos permite reflexionar, en las consideraciones finales, sobre la repercusión del mismo.

En este trabajo presentamos el diseño de una actividad para el desarrollo de la CT6 en una sesión tutorial, realizada con alumnos de primero del Grado de Turismo (GT) que se imparte en la EPSG. 


\section{Objetivos}

Esta innovación ha consistido en el diseño, desarrollo y evaluación de una actividad para trabajar la Competencia de Trabajo en Equipo y Liderazgo (CT6) en la asignatura Informática de Gestión (IG) en el primer curso del Grado de Turismo (GT) que se imparte en la Escuela Politecnica Superior de Gandia (EPSG), en el marco de una Sesión Tutorial realizada dentro del programa PATU.

El objetivo principal es Promover la enseñanza y la evaluación de la competencia transversal Trabajo en equipo y liderazgo de forma integrada con los contenidos y objetivos de la asignatura Informática de Gestión. Otros objetivos secundarios son:

- Mejorar la motivación del alumnado.

- Aumentar el rendimiento académico del alumnado en la asignatura.

\section{Desarrollo de la innovación}

\section{Instrucciones para los alumnos}

Objetivo: preparar entre toda la clase (equipo del proyecto) una única presentación sobre el turismo en Valencia (resultado del proyecto).

Tiempo máximo: 30 minutos (plazo).

Reparto de Tareas: dependen de la posición de los alumnos en la clase (fila y puesto):

\begin{tabular}{|l|cccc|c|}
\hline PUERTA & PUESTO 1 & PUESTO 2 & PUESTO 3 & PUESTO 4 & PASILLO \\
\hline FILA 5 & 5.1 & 5.2 & 5.3 & 5.4 & \\
FILA 4 & 4.1 & 4.2 & 4.3 & 4.4 & \\
FILA 3 & 3.1 & 3.2 & 3.3 & 3.4 & \\
FILA 2 & 2.1 & 2.2 & 2.3 & 2.4 & \\
FILA 1 & 1.1 & 1.2 & 1.3 & 1.4 & \\
\hline
\end{tabular}

Figura 1: posición de los alumnos en el aula (fila y puesto)

A cada fila le corresponderá una zona distinta de la provincia de Valencia:

1. Norte:Sagunt, Camp Turia,...

2. Valencia:Ciudad, Horta,...

3. Xuquer: Albufera, Ribera Baixa, Ribera Alta, Cullera,...

4. Safor: Gandía, Oliva,...

5. Interior: Serranos, Utiel, Bunyol, Ademuz, Cofrentes, Navarrés,.... 


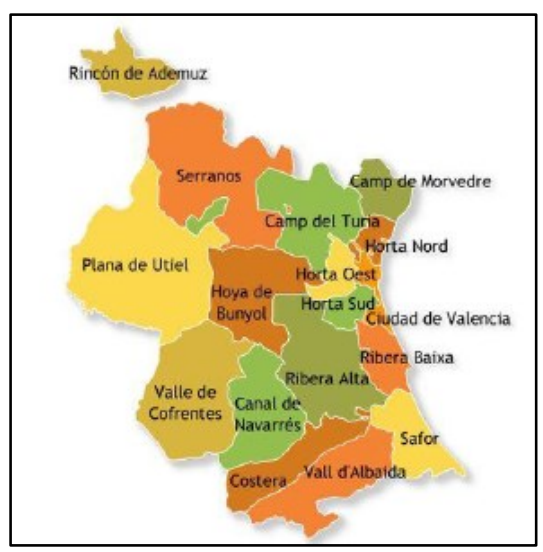

Figura 2: comarcas de la provincia de Valencia

A cada posición en la fila le corresponderá un rol específico ( $n^{0}$ puesto):

1. Coordinador Presentación de la Zona.

2. Crear Presentación sobre el Patrimonio Cultural y Artístico de la Zona.

3. Crear Presentación sobre el Patrimonio Natural de la Zona.

4. Crear Presentación sobre la Gastronomía de la Zona.

Los roles 2, 3 y 4 tienen que preparar una presentación en Drive sobre el tema asignado:

- Crear presentación en GoogleDrive.

- Nombre Documento “zona-rol” (por ejemplo Valencia-Gastronomía).

- Compartir la presentación con el coordinador de la fila.

- Utilizar plantilla Drive sin diseño (facilita elproceso de unir las presentaciones).

- Primera Diapositiva Tipo Título. El Título será la zona y el subtítulo el tema.

- Segunda Diapositiva. Índice de las diapositivas con los contenidos asignados.

- 5 diapositivas sobre el tema (1 imagen+texto). Buscar las imágenes/texto en Google.

- Tiempo máximo 20 minutos.

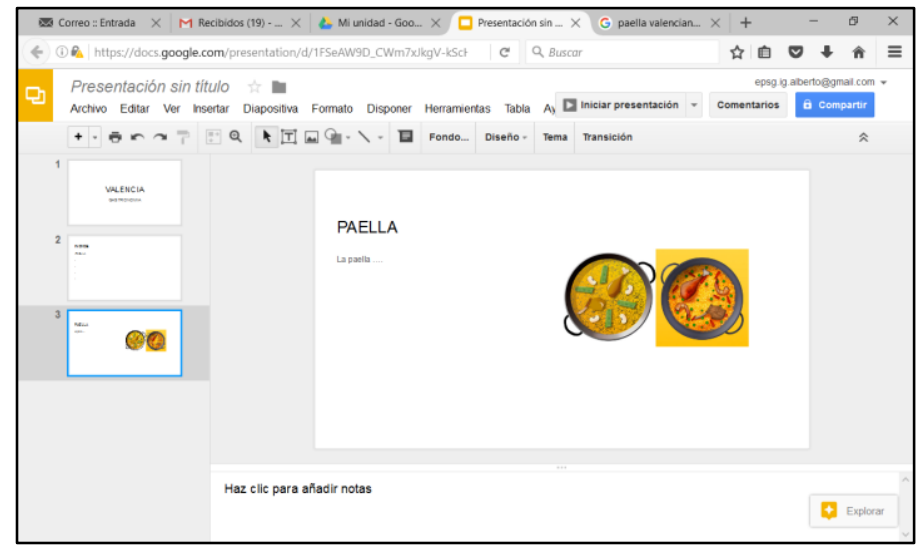

Figura 3: ejemplo de presentación en Drive (Valencia - Gastronomia) 


\section{El coordinador tiene que:}

- Crear la Presentación General de su Zona y llamarla "Nombre de la Zona".

- Compartirla con toda su fila y con el profesor.

- La presentación empezará con 2 diapositivas: título (nombre de la zona) e índice.

- A partir del minuto 20 unirá todas las presentaciones de su fila.

- Comprobar que todos los alumnos de su fila (zona) comparten sus presentaciones

- Comprobar que todas las presentaciones cumplen los requisitos indicados $\left(\mathrm{n}^{\mathrm{o}} \mathrm{de}\right.$ diapositivas y características básicas).

- Comprobar que en su fila se realiza el trabajo en el tiempo previsto (20 minutos).

Tareas de todo el equipo:

- Durante los 10 minutos finales, todos los componentes del equipo pueden revisar, corregir, añadir, quitar, etc. lo que quieran en la presentación del equipo (zona).

A los 30 minutos se parará el cronómetro y no se podrá hacer nada más.

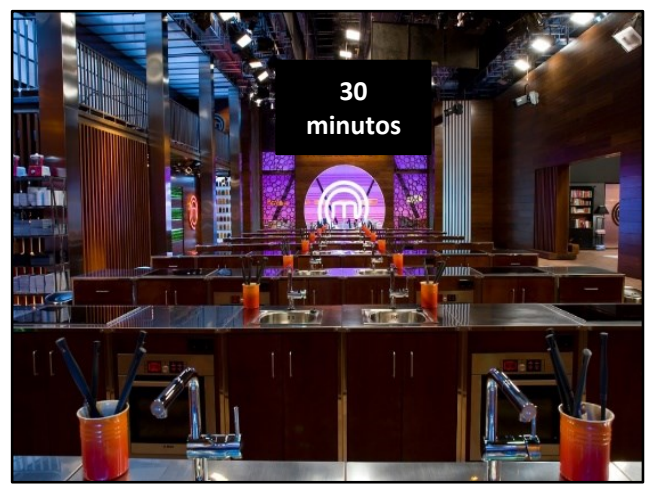

Figura 4: tiempo máximo para realizar la actividad

Para finalizar la actividad, el profesor tiene que:

- Preparar una única presentación uniendo las presentaciones prepardas por toda la clase en una única presentación.

- Subirla a Poliformat para que todos los alumnos de la asignatura tengan acceso a la misma y puedan evaluar el resultado final. 


\section{Resultados (encuesta de evaluación de la actividad)}

Esta experiencia se llevo a cabo el 8 de Noviembre de 2016 con los alumnos de la asignatura Informática de Gestión del primer curso del Grado de Turismo y del Doble Grado Turismo-ADE (la asignatura es común para las 2 titulaciones) en el marco de una Sesión Tutorial del programa PATU prevista para trabajar la CT6.

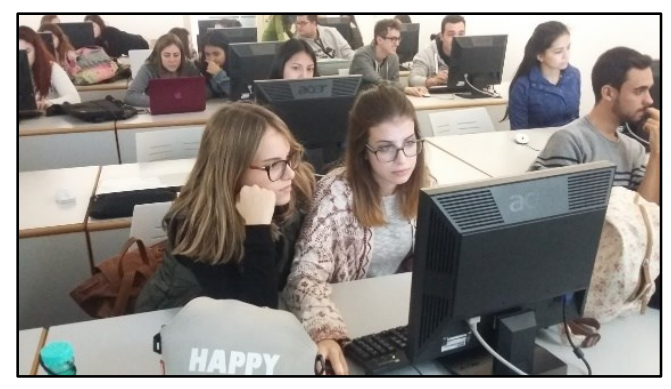

Figura 5: Alumnos de Informática de Gestión trabajando en equipo

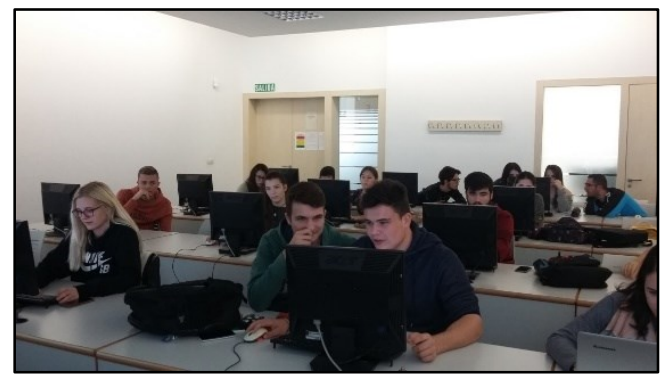

Figura 6: Alumnos de Informática de Gestión trabajando en equipo

Se diseño una encuesta en Drive para que los alumnos evaluaran la actividad. 49 alumnos de los aproximadamente 70 que realizaron la actividad completaron la encuesta. A continuación se muestran las preguntas de esta encuesta y los resultados obtenidos.

Pregunta 1: Como impresión general, me he sentido satisfecho participando en esta actividad sobre el trabajo en grupo

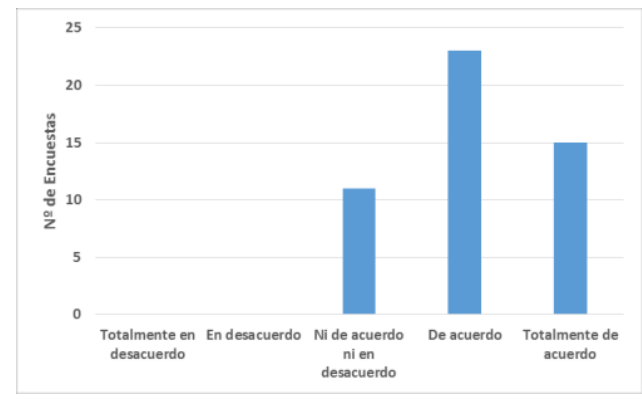

Figura 7: Resultados Encuesta (Pregunta 1) 
Pregunta 2: En particular, me siento satisfecho con respecto a mi aportación al trabajo de nuestro equipo (zona, rol)

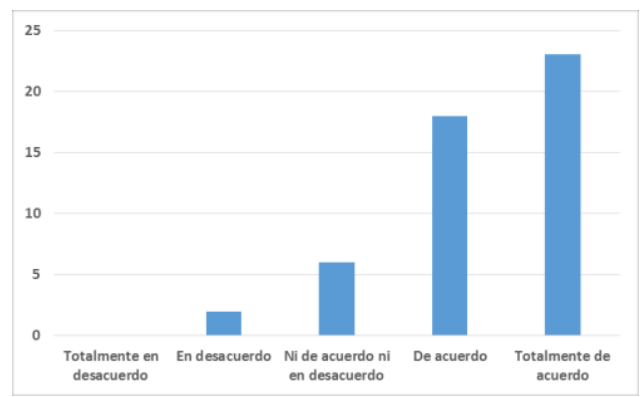

Figura 8: Resultados Encuesta (Pregunta 2)

Pregunta 3: La figura de "coordinador" ha sido útil para alcanzar el objetivo de nuestro equipo

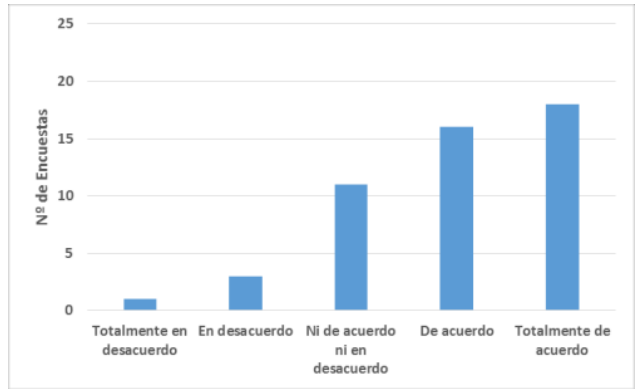

Figura 9: Resultados Encuesta (Pregunta 3)

Pregunta 4: Creo que la calidad del trabajo conseguido por el equipo es superior a la que se hubiera alcanzado trabajando individualmente

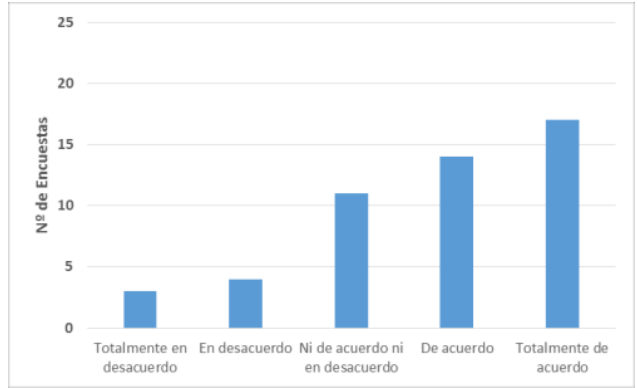

Figura 10: Resultados Encuesta (Pregunta 4) 
Pregunta 5: Todos los miembros del equipo hemos realizado las tareas asignadas en el plazo establecido

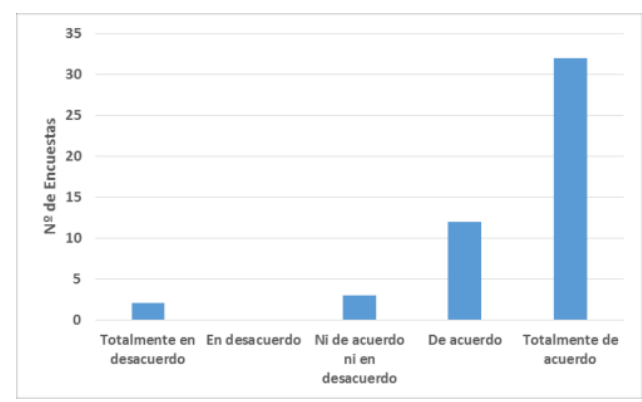

Figura 11: Resultados Encuesta (Pregunta 5)

Pregunta 6: El líder (profesor) ha sido importante para la definición de los objetivos y para saber con claridad lo que teníamos que hacer cada uno

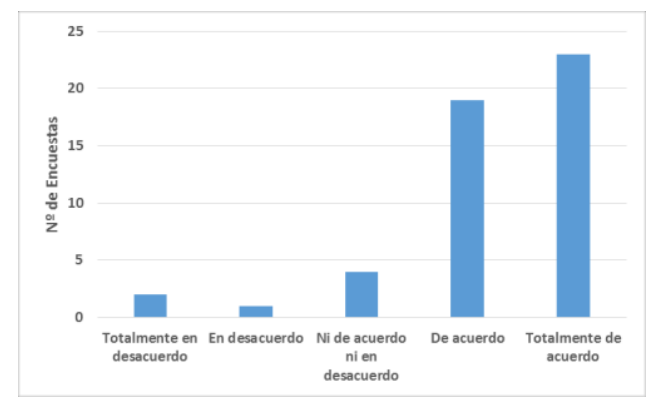

Figura 12: Resultados Encuesta (Pregunta 6)

Pregunta 7: Además me siento satisfecho con respecto a la aportación de mis compañeros al trabajo del equipo

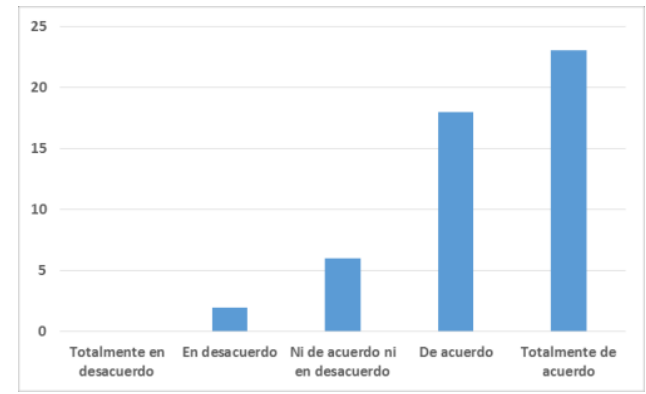

Figura 13: Resultados Encuesta (Pregunta 7) 
Pregunta 8 (respuesta libre): si quieres describe brevemente algo que hayas aprendido trabajando en equipo al realizar esta actividad que quizás no hubieras aprendido haciéndolo solo:

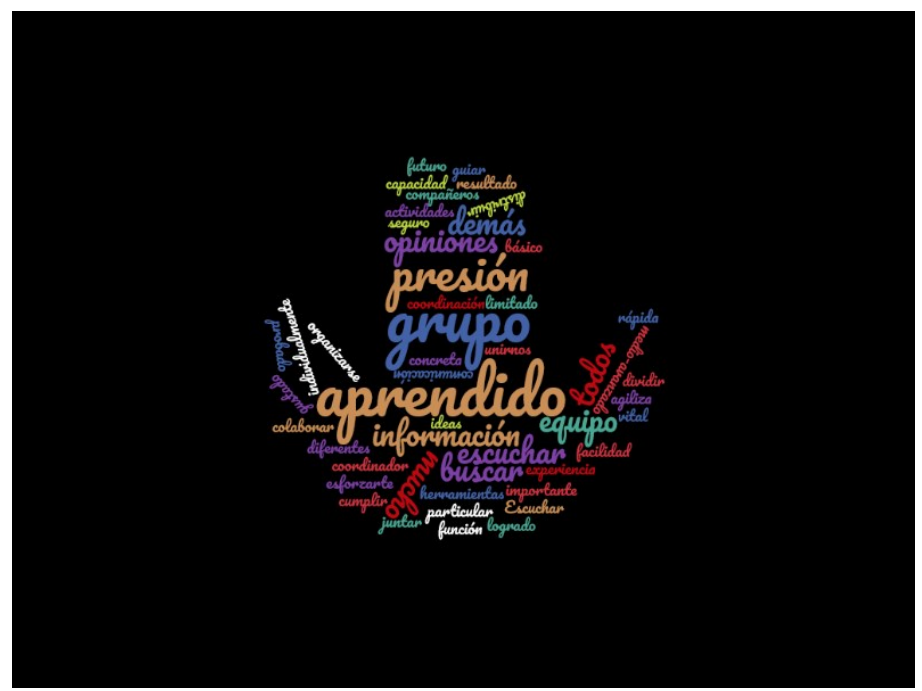

Figura 14: : Resultados Encuesta (Pregunta 9). Nube de Palabras

Pregunta 9 (respuesta libre): Si quieres puedes proponer algún cambio o sugerencia en el desarrollo de la actividad para que el equipo hubiera funcionado mejor:

A continuación se muestran, a modo de ejemplo, algunas de las respuestas proporcionadas por los alumnos:

- Me hubiera gustado haber hablado de otra provincia así de paso podemos aprender culturas, tradiciones.

- Muy buen trabajo.

- En el tiempo que teníamos, y sin planificación previa el desarrollo de la actividad para mí no necesita ningún cambio.

- Más tiempo para distribuirnos las partes del trabajo antes de empezar a realizarlo.

- Más orden a la hora de trabajar.

- Hubiera sido más práctico que las mesas hubiesen estado puestas en forma de círculo, para poder hablar mejor con el grupo todos juntos.

- Más tiempo para hacerlo.

- La distribución del tiempo es esencial.

- Hablándose más entre el equipo.

- Ninguna sugerencia. 


\section{Conclusiones}

Tras el análisis de las respuestas dadas por el alumnado a la encuesta de valoración de la actividad podemos afirmar que el nivel de satisfacción general es alto. Los alumnos valoran de forma positiva tanto el desarrollo de la actividad como su aportación y la aportación de los compañeros y el profesor al trabajo en equipo realizado.

En este caso, y puesto que nos encontramos en un primer nivel de dominio de la CT, por tratarse de alumnos de primer curso, el trabajo en equipo ha estado dirigido por el profesor, siendo él mismo el que ha fijado los criterios para el establecimiento de las normas básicas y el funcionamiento del equipo (número de miembros, el tipo de agrupación, los roles). Los alumnos han valorado de forma positiva el papel del profesor como líder del grupo por lo que parece que la función de orientador, motivador y guía del trabajo se ha cumplido de forma adecuada.

En cursos superiores se prevé diseñar actividades similares pero otorgando un mayor nivel de autonomía a los equipos en la organización de su funcionamiento.

Afirman los alumnos que se han cumplido los objetivos del trabajo y, más aún, que la calidad del trabajo conseguido es superior a la que se hubiera conseguido trabajando de forma individual. Un concepto esencial al referirnos al trabajo en equipo es el de sinergia, según el cual, gracias al concurso y la participación activa y concertada de varios individuos, el resultado del grupo supera a la suma de las aportaciones individuales $(2+2=5)$.

Hemos visto que es posible diseñar, desarrollar y evaluar actividades que permitan a los alumnos la adquisición de competencias transversales como el Trabajo en Equipo y Liderazgo (CT6) de forma coordinada con competencias específicas de la asignatura Informática de Gestión (IG) de primer curso del Grado de Turismo (GT), en este caso la utilización de herramientas informáticas como Google Drive.

Podemos afirmar pues, que hemos conseguido el objetivo propuesto al inicio de esta actividad de promover la enseñanza y la evaluación de la competencia transversal Trabajo en equipo y liderazgo de forma integrada con los contenidos y objetivos de la asignatura Informática de Gestión.

Respecto al objetivo de "Aumentar el rendimiento académico del alumnado en la asignatura" habría que hacer un análisis comparativo de las calificaciones obtenidas por el alumnado en cursos anteriores, en los que no se hubiera implementado la actividad descrita, para poder afirmar que ha habido un aumento en el mismo. O bien, analizar la satisfacción del alumnado en el desarrollo de la misma actividad en el caso de haberla llevado a cabo de forma individual. Sin embargo, y así lo han señalado diversos estudios, parece haber una correlación positiva entre la satisfacción del alumnado y el rendimiento académico, y es obvio que el factor motivacional influye en el aprendizaje. Consideramos que la introducción de este tipo de actividades de equipo pueden repercutir en un aumento del rendimiento académico de los alumnos, aunque de momento no disponemos de datos que permitan evidenciarlo. 


\section{Referencias}

BARKLEY, E.; CROSS, P. y HOWELL, C. (2007): Técnicas de aprendizaje colaborativo. Madrid: Ed. Morata.

BLANCO, A. (2009): Desarrollo y evaluación de competencias en Educación Superior. Madrid: Narcea.

BORRELL F. (2007): Cómo trabajar en equipo. Barcelona: Ed. Gestión 2000.

CABRERA, E. (2008): La colaboración en el aula: Más que uno más uno. Bogotá: Cooperativa Editorial Magisterio.

CANO, E. (2008): La evaluación por competencias en la educación superior Competences assessment in higher education. Revista de curriculum y formación del profesorado. $<$ https://www.ugr.es/ recfpro/rev123COL1.pdf $>>$ [Consulta: 8 de marzo de 2017]

DE MIGUEL, M. (2006): Metodologías de enseñanza y aprendizaje para el desarrollo de competencias. Madrid: Alianza Editorial.

EXLEY, K y DENNICK, R. (2007): Enseñanza en pequeños grupos en Educación Superior. Madrid: Narcea.

FIECHTNER, S. y DAVIS, E. (1992): Why some groups fail? A survey of students' experiences with learning groups. In: Collaborative Learning: A Sourcebook for Higher Education. A. S. Goodsell, M. R. Maher, and V. Tinto, Eds. National Center on Postsecondary Teaching, Learning, and Assessment. University Park, PA: Syracuse University.

JOHNSON, D.; JOHNSON, R. y SMITH, K. (1991): “Cooperative Learning: Increasing College Faculty Instructional Productivity". ASHE-ERIC Higher Education Report No. 4, Washington, DC: The George Washington University. Johnson, D.W.

SÁNCHEZ GONZÁLEZ, Mª P. (2010): Técnicas docentes y sistemas de evaluación en educación superior. Madrid: Narcea.

SERRANO, J.M. (1996). El aprendizaje cooperativo. En Beltrán, J.L. y Genovard, C. (Edit.) Psicología de la Instrucción I. Variables y procesos básicos. Madrid: Editorial Síntesis, S.A. Cap.5, págs. 217-244.

SLAVIN, R. (1999): Aprendizaje cooperativo. Buenos Aires: Aique Grupo Editor.

SPRINGER, L.; STANNE, M. y DONOVAN, S. (1999): Effects of small-group learning on undergraduates in Science, Mathematics, Enrineering and Technology: a meta-analysis. Review of Educational Research, vol. 69, 1, págs. 21-51.

UNIVERSITAT POLITĖCNICA DE VALÈNCIA. Proyecto institucional de competencias transversales. $\quad<\mathrm{http}: / /$ www.upv.es/contenidos/COMPTRAN/info/955712normalc.html> [Consulta: 8 de marzo de 2017]

WEST, M. (2003): El trabajo eficaz en equipo. 1+1=3. Barcelona: Paidós. 